\title{
Conjoined hearts
}

\author{
DANTE ANTONELLI, * LAZER SHMILOVITZ, $\dagger$ MURALEE DHARAN $\ddagger$ \\ From the Department of ${ }^{\star}$ Cardiology, $†$ Neonatal Intensive Care Unit, and the $\ddagger$ Institute of Pathology \\ Central Emek Hospital, Afula, Israel
}

SUMMARY Thoracopagus twins were delivered at 37 weeks' gestation by caesarean section. Respiratory distress was present and mechanical ventilation was needed; 36 hours after delivery severe lactic acidosis developed and the twins died. The pericardial sac was common and the hearts were conjoined as a single structure with ventricular fusion.

Thoracopagus is the most common variety of conjoined twins. ${ }^{1}$ About $75 \%$ of thoracopagus twins have a conjoined heart and in $90 \%$ the pericardial sac is common for both members. ${ }^{2}$ Other organs or systems may be common to both twins and in most cases their surgical separation is possible. The separation of hearts with fused ventricles, however, is not feasible and for this reason preoperative cardiovascular investigation in conjoined twins is important when surgical intervention is considered. We describe the cardiovascular abnormalities in a set of thoracopagus twins that we examined.

\section{Case report}

The twins, both female, were born after an elective caesarean section at 37 weeks' gestation. The mother was a 23 year old primipara. Both patients come from families in which there are twins. The combined birth weight was $4400 \mathrm{~g}$. They were facing each other and were conjoined at the thoracic cage and upper part of the abdomen. The umbilical cord led into the twins at a single umbilicus with a single artery. Twin 1 had a cleft lip and twin 2 a cleft palate. Both responded to stimuli but were hypotonic. Respiratory distress was present soon after birth and this was treated with mechanical ventilation and $100 \%$ oxygen through an endotracheal tube. Blood gas values indicated metabolic acidosis and cyanosis was slight. Femoral pulses were palpable in each twin but were weaker in twin 1 . No murmurs or abnormal heart sounds were noted. The heart rates were synchronous and ranged from 140 to 150 beats $/ \mathrm{min}$. The electrocardiogram was recorded from each twin separately and showed a single QRS complex of nor-

Requests for reprints to Dr Dante Antonelli, Department of Cardiology, Central Emek Hospital, Afula 18101, Israel. mal width; in twin 1 the electrocardiogram showed sinus rhythm and left axis deviation, whereas in twin 2 coronary sinus rhythm was present. Cross sectional echocardiographic examination was of poor quality and it was possible to detect only the presence of a single heart but not the specific cardiac malformations. Thirty six hours after delivery severe lactic acidosis developed and the twins died.

\section{FINDINGS AT NECROPSY}

When the thoracic cavity was opened a common anterior mediastinum was found. A single heart which weighed $18 \mathrm{~g}$ was found in a common pericardial sac; it was distributed equally on both sides of the midline of the combined chest. When viewed from the posterior aspect twin 1 was on the observer's right and twin 2 on the observer's left. The terms "right" and "left" will hereafter be used in relation to each twin. The atrium was a common tube like chamber $4 \mathrm{~cm}$ long with a diameter of $1.5 \mathrm{~cm}$ (fig la). It was partly divided into two halves by a circular ridge of tissue $1 \mathrm{~cm}$ in width. The half on the side of twin 1 showed a further partial subdivision into two chambers by another circular ridge of tissue surrounding a patent foramen ovale; the lower margin of this resembled the arched superior border of an ostium primum. The atrium on the side of twin 2 was not subdivided and corresponded to a single atrium. Each half of the common atrium had two appendages; one resembled a left appendage and the other larger one resembled a right atrial appendage (figs $1 \mathrm{~b}$ and $1 \mathrm{c}$ ). In each twin a superior and an inferior vena cava were present. The inferior vena cava of twin 2 entered near the base of the right appendage. Four pulmonary veins entered both the left atrium of twin 1 and the single atrium of twin 2 . In twin 1 the atrioventricular valve resembled that found in persistent comrion atrioventricular canal 

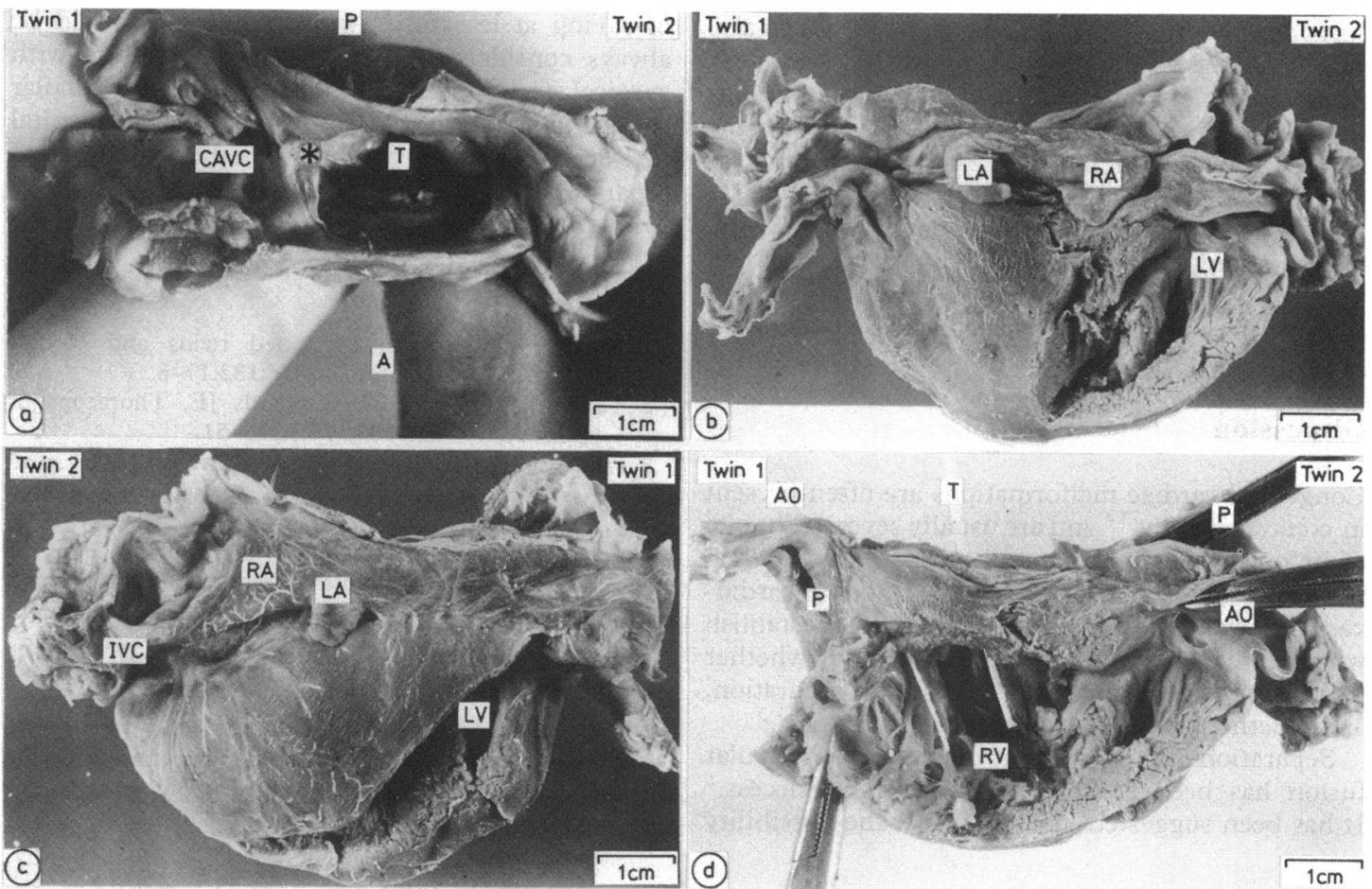

Fig 1 (a) Interior of common atrial chamber viewed from above. $T$, tricuspid valve; CAVC, common atrioventricular canal; $A$, anterior; $P$, posterior. ${ }^{*} T$ issue ridge partly dividing the common atrium. (b) Anterior view of the common heart opened along its left border and displaced laterally. Right and left atrial appendages (RA and LA) of twin 1 are shown. $L V$, left ventricle of twin 2. (c) Posterior view of the common heart opened along its right border showing the left ventricle of twin 1 ( $L V$ ) and the right and left atrial appendages ( $R A$ and LA respectively) and inferior vena cava (IVC) of twin 2. (d) Anterior view of the heart opened along its left border and at the base of the anterior wall of the common right ventricle and displaced to the right. $A O$, aorta; $P$, pulmonary artery; $T$, tricuspid valve; $R V$, common right ventricle; $L V$, left ventricle.

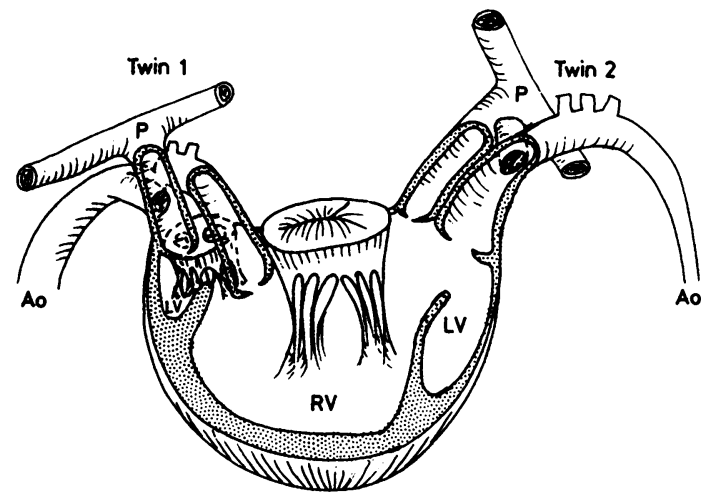

Fig 2 Schematic representation of ventricular complex and great vessels. $P$, pulmonary artery; Ao, aorta; $R V$, common right ventricle; $L V$, left ventricle. and in twin 2 it appeared to be tricuspid.

The anatomical left ventricle of twin 1 was hypoplastic. There was a common anatomical right ventricle with two hypertrophic papillary muscles (the anterior was on the right side and the posterior on the left side) with no evidence of subdivision. The left ventricle of twin 2 had no atrioventricular valve and communicated with the common right ventricle through an upper interventricular septal defect that was $6 \mathrm{~mm}$ in diameter. In twin 1 the aorta arose from the common right ventricle anteriorly and to the left of the pulmonary artery; it passed posteriorly to the pulmonary artery and formed a right sided arch. A moderate coarctation was present proximal to a large ductus arteriosus. The pulmonary artery arose from the hypoplastic left ventricle (fig $1 \mathrm{~d}$ ).

In twin 2 the aorta arose from the common right ventricle. A ductus arteriosus arose $2 \mathrm{~cm}$ above the aortic valve and proximal to the origin of the brachiocephalic arteries. Beyond the distal part of the left sided arch the aorta became hypoplastic. The 
aorta did not cross the pulmonary artery, which also arose from the common right ventricle (double outlet right ventricle) (fig 2). Serial histological sections showed a bifurcating atrioventricular system in the septum of twin 1 but not twin 2. In neither twin was an atrioventricular node found.

In addition to the cardiovascular anomalies, the liver was conjoined and the small bowel was common to both twins. Normally formed female urogenital, central nervous, and respiratory systems were present.

\section{Discussion}

Congenital cardiac malformations are often present in conjoined twins ${ }^{34}$ and are usually severe. The site of union of hearts is of practical importance when surgical intervention is considered and the cardiovascular evaluation must be directed to establish whether there is only a pericardial union, whether there is atrial connection but ventricular separation, and whether there is a ventricular connection. ${ }^{3}$

Separation of thoracopagus twins with ventricular fusion has been attempted but without success. ${ }^{5}$ It has been suggested, however, that the possibility of saving at least one twin of the pair should be always considered. ${ }^{6}$ Despite recent progress with surgical techniques we consider that ventricular connection is still an unmanageable congenital malformation and we doubt whether attempts to separate fused ventricles can lead to satisfactory results.

\section{References}

1 Noonan JA. Twins, conjoined twins and cardiac defects. Am $\mathcal{F}$ Dis Child 1978;132:17-8.

2 Tandom R, Sterns LP, Edwards JE. Thoracopagus twins. Arch Pathol 1974;98:248-51.

3 Izukawa T, Langford Kidd BS, Moes CAF, et al. Assessment of the cardiovascular system in conjoined thoracopagus twins. Am $\mathcal{F}$ Dis Child 1978;132:19-24.

4 Patel R, Fox K, Dawson J, Taylor JFN, Graham GR. Cardiovascular anomalies in thoracopagus twins and the importance of preoperative cardiac evaluation. Br Heart $\mathcal{F}$ 1977;39:1254-8.

5 Edwards WD, Hagel DR, Thompson J, Wharton M, Edwards JE. Conjoined thoracopagus twins. Circulation 1977;56:491-7.

6 Kaplan M, Glaser J, Eidelman AI. Early cardiac evaluation of thoracically conjoined twins. Cardiology 1983;70:152-5.

\section{Notices}

\section{British Cardiac Society}

The Autumn Meeting will be held at the Wembley Conference Centre, London, on 25 to 27 November 1986 , and the closing date for receipt of abstracts was 11 July 1986.

The Annual General Meeting for 1987 will take place in Dundee on 8 and 9 April 1987, and the closing date for receipt of abstracts will be 6 January 1987.

\section{Interaction between heart and lung}

An International Congress on Interaction between Heart and Lung sponsored by the European Society of Cardiology and the European Society for Clinical Respiratory Physiology will be held in Munich on 9 to 11 April 1987. Inquiries to Dr H-P Emslander, First Medical Clinic, Klinikum rechts der Isar der TUM, Ismaninger Strasse 22, D-8000 Munich 80, Federal Republic of Germany. 